\title{
Concurrent radiotherapy with oral fluoropyrimidine versus gemcitabine in locally advanced pancreatic cancer: a systematic review and meta-analysis
}

This article was published in the following Dove Press journal:

OncoTargets and Therapy

9 November 2015

Number of times this article has been viewed

\section{Yong-Feng Yang' \\ Xiao-Hui Cao' \\ Chao-En Bao' \\ Xin Wan ${ }^{2}$}

'Department of Radiation Oncology, Third Hospital of Hebei Medical University, Shijiazhuang, People's Republic of China; ${ }^{2}$ Department of Radiation Oncology, Fourth Hospital of Hebei Medical University, Shijiazhuang, People's Republic of China
Correspondence: Xin Wan Department of Radiation Oncology, Fourth Hospital of Hebei Medical University, No 12 Jiankang Road, Shijiazhuang, Hebei Province, 0500II, People's Republic of China Tel +86 31186095588

Email wanxin20I50606@I63.com
Background: Gemcitabine (GEM) is the most widely utilized systemic agent in combination with radiation therapy (RT) for treating locally advanced pancreatic cancer (LAPC) in the concurrent setting. Despite recent interest in using two novel oral fluoropyrimidines (FUs), capecitabine and S-1, in this setting, there is a lack of randomized controlled trials (RCTs) to support this approach.

Methods: Trials published between 1994 and 2014 were identified by an electronic search of public databases (Medline, Embase, and the Cochrane Library). All prospective studies were independently identified by two authors for inclusion. Demographic data, treatment response, objective response rate (ORR), progression-free and overall survival (PFS and OS, respectively), and toxicities were extracted and analyzed using comprehensive meta-analysis software (version 2.0).

Results: Twenty-three cohorts with 843 patients were included: 497 patients were treated with GEM and 346 patients were treated with oral FU. Pooled OS was significantly higher at 1 and 2 years for S-1 plus RT than for GEM plus RT (relative risk [RR] 1.27; 95\% confidence interval [CI], 1.00-1.65; $P=0.03$; and RR 1.75; 95\% CI, 1.18-2.60, $P=0.002$, respectively), while 1-year PFS and ORR were not significantly different between S-1 and GEM-based chemoradiotherapy ( $P=0.37$ and $P=0.06$, respectively). Additionally, comparable efficacy was found between capecitabine and GEM-based chemoradiotherapy in terms of OS, PFS, and ORR. As for grade 3 and 4 acute toxicity, oral FU plus RT significantly reduced the risk of developing hematologic toxicities, nausea, and vomiting when compared to GEM plus RT $(P<0.001)$.

Conclusions: Oral FU plus RT may be a safe and feasible regimen for patients with LAPC, with similar efficacy and low rate of toxicities compared with GEM plus RT. Our findings support the need to compare S-1 with GEM in the concurrent setting in large prospective RCTs due to its potential survival benefits.

Keywords: pancreatic cancer, chemoradiotherapy, oral fluoropyrimidine, gemcitabine, meta-analysis

\section{Introduction}

Pancreatic cancer (PC) is the 12th most commonly diagnosed malignancy, yet it is the eighth leading cause of cancer-related mortality worldwide, with an estimated 266,000 deaths in 2008. ${ }^{1}$ Of all treatment modalities available for PC, only resection offers an opportunity for a cure. However, only $10 \%-15 \%$ of patients have localized and resectable disease at diagnosis. Approximately $50 \%$ of PC patients present with distant metastatic disease, and 30\% present with localized and unresectable disease. For these patients, both chemotherapy alone and chemoradiotherapy (CRT) are regarded as acceptable treatment options. ${ }^{2-4}$ However, randomized controlled trials that compared 
the two strategies have had conflicting results ${ }^{4,5}$ and therefore have not been able to define a preferred standard of care.

Currently, both fluoropyrimidines (FU) and gemcitabine (GEM) have been used concurrently with radiation therapy (RT) in patients with locally advanced pancreatic cancer (LAPC). FU drugs including 5-fluorouracil, capecitabine and S-1 have proven to be effective in LAPC treatment. In 1981, a modest prolongation of survival and a median survival of 10 months in LAPC patients treated with 5-fluorouracilbased CRT was reported by the Gastrointestinal Tumor Study Group (GITSG). ${ }^{6}$ Thus, 5-fluorouracil-based CRT is the most widely used treatment for LAPC.

During the past decades, GEM radiosensitization has been used in some studies because of its systemic activity in pancreatic cancer and its potent radiosensitizing properties..$^{7-10}$ In addition, a recent meta-analysis based on three small randomized controlled trials (RCTs) and one retrospective study suggested a survival benefit of GEM compared with 5-fluorouracil-based CRT, ${ }^{11}$ but at the cost of greater toxicity. Therefore, the optimal regimen for CRT remains elusive. Recently, two novel oral FU drugs, capecitabine and $\mathrm{S}-1$, have been widely used in conjunction with radiotherapy for LAPC patients due to their improved therapeutic index, more favorable pharmacokinetics (similar to those of protracted infusion of 5-fluorouracil), and their convenient oral administration without the need for central venous access and an ambulatory infusion pump. However, whether oral FU-based CRT is better than GEM-based CRT for LAPC remains uncertain. Due to the controversy of the effect of oral FU-based CRT in LAPC, we conducted the present systematic review and meta-analysis to evaluate the efficacy and toxicities of oral FU-based CRT compared with GEM-based CRT for the treatment of LAPC.

\section{Materials and methods}

\section{Study design}

We developed a protocol that defined inclusion criteria, search strategy, outcomes of interest, and analysis plan. The reporting of the current systematic review adheres to the Preferred Reporting Items for Systematic Reviews and Meta-Analyses (PRISMA) statements. ${ }^{12}$

\section{Identification and selection of studies}

To identify studies for inclusion in our current systematic review and meta-analysis, we did a broad search of four databases, including Embase, Medline, the Cochrane Central Register of Controlled Trials, and the Cochrane Database of Systematic Reviews, from the date of inception of every database to August 2014. The search included the following terms: "pancreatic neoplasms", "pancreatic cancer", "pancreatic carcinoma", "pancreatic adenocarcinoma", "gemcitabine", "gemzar", "oral fluoropyrimidines", "capecitabine”, "xeloda", "S-1", "radiotherapy", and "chemotherapy". Additional references were searched through manual searches of the reference lists and specialist journals. No language restrictions were applied.

To be eligible for inclusion in our present systematic review and meta-analysis, study populations (referred to hereafter as cohorts) had to meet all the following criteria: 1) patients with LAPC; 2) treatment with GEM-based CRT, capecitabine-based CRT, or S-1 based CRT, while combined chemotherapy plus RT were excluded for analysis in our current study; 3 ) reported outcomes of interest (ie, objective response rate, survival, and complications); and 4) from an original study (ie, RCT, non-randomized clinical trial, observational studies, or case series).

\section{Data extraction}

Two investigators screened the titles and abstracts of potentially relevant studies. We retrieved the full text of relevant studies for further review by the same two reviewers. A third senior investigator resolved any discrepancies between reviewers. If reviewers suspected an overlap of cohorts in a report, they contacted the corresponding author for clarification; we excluded studies with a clear overlap.

The same pair of reviewers extracted study details independently, using a standardized pilot-tested form. A third investigator reviewed all data entries. We extracted the following data: author, study design, study period, median age, interventions (concurrent chemotherapy, radiation dose, and fractionation schedule), sample size, and outcomes of interest. We defined outcomes of interest as overall survival (OS), progression-free survival (PFS), objective response rate (ORR), and toxic effects. We assessed survival outcomes at 1 and 5 years, while we also assessed 1-year PFS, ORR, and toxicities.

To assess quality, since we included non-comparative (uncontrolled) studies in our current systematic review and meta-analysis, we used the Newcastle-Ottawa quality assessment scale. ${ }^{13}$ We selected items that focused on representativeness of study patients, demonstration that the outcome of interest was not present at the start of the study, adequate assessment of outcome, sufficient length of follow-up to allow outcomes to arise, and adequacy of follow-up (Table S1). 


\section{Statistical analysis}

We pre-specified the analysis plan in the protocol. We analyzed all patients who started GEM or oral FU-based CRT, regardless of their adherence to treatment. We calculated event rates of outcome (the proportion of patients who developed outcomes of interest) from the included cohorts for both GEM and oral FU-based CRT. We pooled log-transformed event rates with DerSimonian and Laird random-effect models and assessed heterogeneity using the Mantel-Haenszel test. ${ }^{14}$ We used the test of interaction proposed by Altman to compare log-transformed rates of outcomes between GEM and oral FU-based CRT. ${ }^{15} \mathrm{~A}$ statistical test with a $P$-value $<0.05$ was considered significant. To account for the potential effect of publication bias, we used the Duval and Tweedie non-parametric trim-and-fill method. ${ }^{16}$ To measure overall heterogeneity across the included cohorts, we calculated the $I^{2}$ statistic, with $I^{2}>50 \%$ indicating high heterogeneity. We assessed potential publication bias by visual inspection of the symmetry of funnel plots and with the Egger regression asymmetry test. We did all statistical analyses with Stata version 12.1 (StataCorp LP, College Station, TX, USA) and comprehensive metaanalysis software version 2.0 (Biostat Inc, Englewood, NJ, USA).

\section{Results \\ Search results}

A total of 317 studies were identified from the database search, of which 51 reports were retrieved for full-text evaluation. Exactly 23 cohorts from 22 trials $^{4,7,9,17-35}$ met the inclusion criteria and were included in the present systematic review (Figure 1). We only found one phase II RCT that directly compared GEM-based CRT with capecitabine-based CRT. Table 1 shows the characteristics of the included studies. Overall, 843 patients were included, with a median age of 64.7 years (range, 59-68.5 years) for the GEM-based group and 63.1 years (range, 58-67.5 years) for the oral FU group. The median OS was longer in oral FU-based CRT than GEM-based CRT (Table 2), while median radiation dose or median PFS did not differ between groups.

Methodological quality of the included studies was fair; most studies provided adequate outcome ascertainment, enrolled a representative sample of patients, and had an acceptable length of follow-up (Figure 2). However, comparative evidence was at high risk of bias, because we compared data across studies, not within them, and selection bias was likely to be present. Assessment of publication bias was not done because data would be unreliable in view of

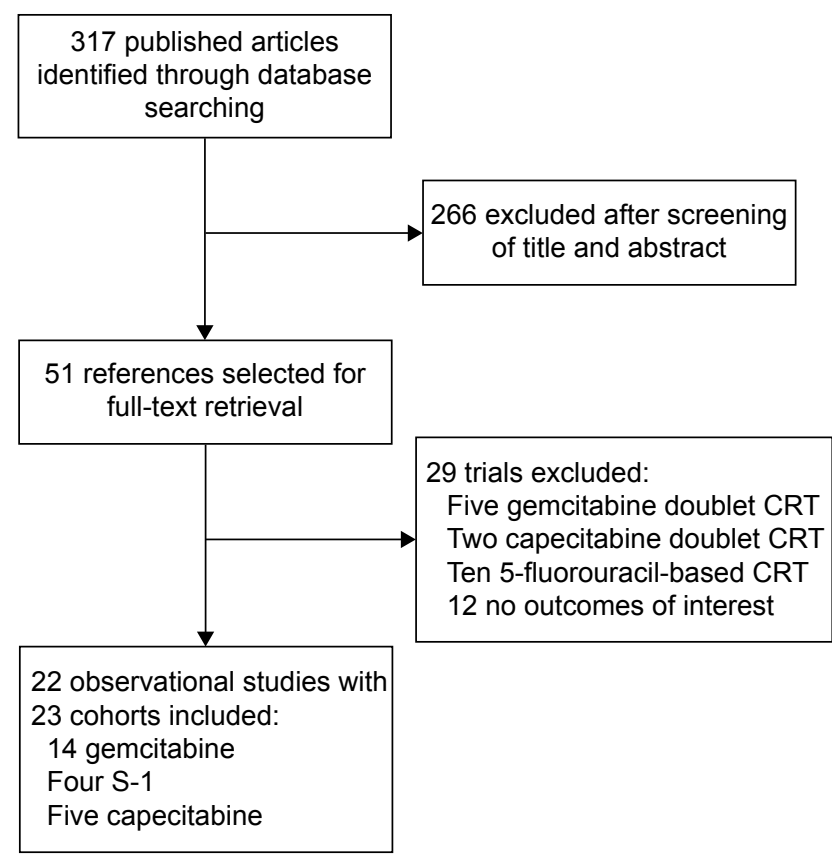

Figure I Selection process for clinical trials included in the meta-analysis. Abbreviation: CRT, chemoradiotherapy.

the few studies included for each treatment group and their high heterogeneity $\left(I^{2}>50 \%\right)$ in most analyses.

\section{Pooled results of primary outcomes}

The pooled event rate of OS for S-1-based CRT was significantly higher than that for GEM-based CRT at 1 year (relative risk [RR] 1.27; 95\% CI, 1.00-1.65; $P=0.03$ ), and at 2 years (RR $1.75 ; 95 \%$ CI, 1.18-2.60; $P=0.002$; Table 3 ). ORR and 1-year PFS were not significantly different between S-1 and GEM-based CRT ( $P=0.06$ and $P=0.37$, respectively). Additionally, comparable efficacy was found between capecitabine and GEM-based CRT in terms of OS, PFS, and ORR (Table 3).

\section{Pooled high-grade acute toxicities}

Table 4 shows the overall acute occurrence of high-grade ( $\geq$ grade 3 ) toxic effects with oral FU versus GEM-based CRT. The incidence of high-grade acute hematologic toxicities, nausea, and vomiting was significantly lower in the oral FU-based CRT group than in the GEM-based CRT group (Table 4). Additionally, equivalent frequencies of high-grade diarrhea and fatigue were found between oral FU and GEMbased CRT ( $P=0.07$ and $P=0.05$, respectively).

\section{Discussion}

LAPC has a poor prognosis, and treatment advances have evolved slowly. Until now, the optimal therapy for patients with LAPC remains elusive. Since a series of seminal studies 
Table I Baseline characteristics of 23 cohort groups for meta-analysis

\begin{tabular}{|c|c|c|c|c|c|c|c|c|c|c|}
\hline Author & Year & $\begin{array}{l}\text { Study } \\
\text { design }\end{array}$ & $\begin{array}{l}\text { Patients, } \\
\text { n }\end{array}$ & $\begin{array}{l}\text { Concurrent } \\
\text { chemotherapy }\end{array}$ & $\begin{array}{l}\text { Median } \\
\text { age, years }\end{array}$ & $\begin{array}{l}\text { Radiation dose, } \\
\text { Gy/Fx dose/Fx }\end{array}$ & $\begin{array}{l}\text { Radiation } \\
\text { technique }\end{array}$ & $\begin{array}{l}\text { Median OS, } \\
\text { months }\end{array}$ & $\begin{array}{l}\text { Median PFS, } \\
\text { months }\end{array}$ & ORR, \% \\
\hline $\begin{array}{l}\text { de Lange } \\
\text { et } \mathrm{al}^{7}\end{array}$ & 2002 & $P$ & 24 & GEM $300 \mathrm{mg} / \mathrm{m}^{2}$ & 63 & $24 \mathrm{~Gy} / 8 \mathrm{~Gy} / 3 \mathrm{Fx}$ & 3D-CRT & 10 & 7 & $29.20 \%$ \\
\hline $\begin{array}{l}\text { Epelbaum } \\
\text { et } \mathrm{al}^{35}\end{array}$ & 2002 & $P$ & 20 & GEM $400 \mathrm{mg} / \mathrm{m}^{2}$ & 66 & $50.4 \mathrm{~Gy} / \mathrm{I} .8 \mathrm{~Gy} / 28 \mathrm{Fx}$ & 3D-CRT & 8 & NR & $15 \%$ \\
\hline $\begin{array}{l}\text { Blackstock } \\
\text { et al }\end{array}$ & 2003 & $P$ & 43 & $\begin{array}{l}\text { GEM } 40 \mathrm{mg} / \mathrm{m}^{2} \\
\text { twice }\end{array}$ & 59 & $50.4 \mathrm{~Gy} / \mathrm{I} .8 \mathrm{~Gy} / 28 \mathrm{Fx}$ & NR & 8.2 & NR & NR \\
\hline $\begin{array}{l}\text { Okusaka } \\
\text { et } \mathrm{al}^{33}\end{array}$ & 2004 & $P$ & 42 & GEM $250 \mathrm{mg} / \mathrm{m}^{2}$ & 59 & $50.4 \mathrm{~Gy} / \mathrm{l} .8 \mathrm{~Gy} / 28 \mathrm{Fx}$ & NR & 9.5 & 4.4 & $21 \%$ \\
\hline Li et $\mathrm{al}^{9}$ & 2003 & $P$ & 18 & GEM $600 \mathrm{mg} / \mathrm{m}^{2}$ & 68.5 & $\begin{array}{l}50.4-6 / .2 \mathrm{~Gy} / \mathrm{l} .8 \mathrm{~Gy} / \\
28-34 \mathrm{Fx}\end{array}$ & 3D-CRT & 14.5 & 7.1 & $50 \%$ \\
\hline $\begin{array}{l}\text { Magnino } \\
\text { et } \mathbf{a}^{32}\end{array}$ & 2005 & $\mathrm{R}$ & 23 & $\begin{array}{l}\text { GEM } 100 \mathrm{mg} / \mathrm{m}^{2} \text { or } \\
50 \mathrm{mg} / \mathrm{m}^{2}\end{array}$ & 62 & $45 \mathrm{~Gy} / \mathrm{I} .8 \mathrm{~Gy} / 25 \mathrm{Fx}$ & 3D-CRT & 14 & NR & $22 \%$ \\
\hline $\begin{array}{l}\text { Murphy } \\
\text { et al| }\end{array}$ & 2007 & $\mathrm{R}$ & 74 & GEM $1,000 \mathrm{mg} / \mathrm{m}^{2}$ & 64.5 & $\begin{array}{l}20-42 \mathrm{~Gy} / \mathrm{I} .3-2.8 \\
\mathrm{~Gy} / 15 \mathrm{Fx}\end{array}$ & NR & 11.2 & 6.4 & $15 \%$ \\
\hline $\begin{array}{l}\text { Yamazaki } \\
\text { et al }{ }^{29}\end{array}$ & 2007 & $\mathrm{R}$ & 22 & GEM I,000 mg/m² & 66 & $50 \mathrm{~Gy} / 2 \mathrm{~Gy} / 25 \mathrm{Fx}$ & 3D-CRT & 16 & & $32 \%$ \\
\hline $\begin{array}{l}\text { Small Jr } \\
\text { et al }{ }^{28}\end{array}$ & 2008 & $P$ & 41 & GEM I,000 mg/m² & 59.5 & $36 \mathrm{~Gy} / 2.4 \mathrm{~Gy} / \mathrm{I} 5 \mathrm{Fx}$ & 3D-CRT & NR & NR & $5 \%$ \\
\hline $\begin{array}{l}\text { Cardenes } \\
\text { et } \mathrm{al}^{24}\end{array}$ & 2011 & $P$ & 28 & GEM $600 \mathrm{mg} / \mathrm{m}^{2}$ & 65 & $50.4 \mathrm{~Gy} / \mathrm{I} .8 \mathrm{~Gy} / 28 \mathrm{Fx}$ & 3D-CRT & 10.3 & 6 & $21 \%$ \\
\hline $\begin{array}{l}\text { Huang } \\
\text { et } \mathrm{al}^{23}\end{array}$ & 2011 & $\mathrm{R}$ & 55 & GEM I,000 mg/m² & $N R$ & $\begin{array}{l}22-42 \mathrm{~Gy} / 2 \mathrm{~Gy} / \\
|\mathrm{I}-2| \mathrm{Fx}\end{array}$ & 3D-CRT & 12.5 & NR & NR \\
\hline $\begin{array}{l}\text { Loehrer } \mathrm{Sr} \\
\text { et al }{ }^{4}\end{array}$ & 2011 & $P$ & 34 & GEM $600 \mathrm{mg} / \mathrm{m}^{2}$ & 66 & $50.4 \mathrm{~Gy} / \mathrm{I} .8 \mathrm{~Gy} / 28 \mathrm{Fx}$ & 3D-CRT & 11.1 & 6 & $6 \%$ \\
\hline $\begin{array}{l}\text { Wang } \\
\text { et } \mathrm{a}^{20}\end{array}$ & 2012 & $\mathrm{R}$ & 35 & GEM I,000 mg/m² & NR & $50.4 \mathrm{~Gy} / \mathrm{I} .8 \mathrm{~Gy} / 28 \mathrm{Fx}$ & 3D-CRT & 13 & NR & $74.30 \%$ \\
\hline $\begin{array}{l}\text { Mukherjee } \\
\text { et a }\left.\right|^{17}\end{array}$ & 2013 & $P$ & 38 & GEM 300 mg/m² & 66 & $50.4 \mathrm{~Gy} / \mathrm{I} .8 \mathrm{~Gy} / 28 \mathrm{Fx}$ & NR & 13.4 & 10 & $19 \%$ \\
\hline Kim et $\mathrm{al}^{27}$ & 2009 & $P$ & 25 & $\mathrm{~S}-\mathrm{I} 40 \mathrm{mg} / \mathrm{m}^{2}$ & 67.5 & $50.4 \mathrm{~Gy} / \mathrm{I} .8 \mathrm{~Gy} / 28 \mathrm{Fx}$ & 3D-CRT & 12.9 & 6.5 & $24 \%$ \\
\hline $\begin{array}{l}\text { Jackson } \\
\text { et } \mathrm{al}^{26}\end{array}$ & 2010 & $\mathrm{R}$ & 30 & CAP $500-600 \mathrm{mg} / \mathrm{m}^{2}$ & 65 & $50.4 \mathrm{~Gy} / \mathrm{I} .8 \mathrm{~Gy} / 28 \mathrm{Fx}$ & 3D-CRT & 9.7 & 8.8 & $17 \%$ \\
\hline Kim et $\mathrm{al}^{25}$ & 2010 & $\mathrm{R}$ & 39 & CAP $850 \mathrm{mg} / \mathrm{m}^{2}$ & 61 & $\begin{array}{l}\text { 44-54 Gy/l.8 Gy/ } \\
24-30 \mathrm{Fx}\end{array}$ & 3D-CRT & 14.3 & 5.1 & $41.70 \%$ \\
\hline $\begin{array}{l}\text { Sudo } \\
\text { et } \mathrm{a}^{22}\end{array}$ & 2011 & $P$ & 34 & $\mathrm{~S}-180 \mathrm{mg} / \mathrm{m}^{2}$ & 63 & $50.4 \mathrm{~Gy} / \mathrm{l} .8 \mathrm{~Gy} / 28 \mathrm{Fx}$ & 3D-CRT & 16.8 & 8.7 & $41 \%$ \\
\hline Saif et $\mathrm{al}^{30}$ & 2007 & $P$ & 20 & CAP I, $600 \mathrm{mg} / \mathrm{m}^{2}$ & 58 & $50.4 \mathrm{~Gy} / \mathrm{I} .8 \mathrm{~Gy} / 28 \mathrm{Fx}$ & 3D-CRT & 12 & & $20 \%$ \\
\hline $\begin{array}{l}\text { Shinchi } \\
\text { et } \mathrm{al}^{21}\end{array}$ & 2012 & $P$ & 50 & $\mathrm{~S}-180 \mathrm{mg} / \mathrm{m}^{2}$ & 66 & $50 \mathrm{~Gy} / 2 \mathrm{~Gy} / 25 \mathrm{Fx}$ & 3D-CRT & 14.3 & 6.7 & $30 \%$ \\
\hline $\begin{array}{l}\text { Ikeda } \\
\text { et al }\left.\right|^{19}\end{array}$ & 2013 & $P$ & 60 & $\mathrm{~S}-\mathrm{I} 80 \mathrm{mg} / \mathrm{m}^{2}$ & 64 & $50.4 \mathrm{~Gy} / \mathrm{I} .8 \mathrm{~Gy} / 28 \mathrm{Fx}$ & NR & 16.2 & 9.7 & $27 \%$ \\
\hline Kim et al ${ }^{18}$ & 2013 & $\mathrm{R}$ & 52 & CAP $800 \mathrm{mg} / \mathrm{m}^{2}$ & 63 & $55.8 \mathrm{~Gy} / \mathrm{I} .8 \mathrm{~Gy} / 3 \mathrm{I} \mathrm{Fx}$ & NR & 12.5 & NR & $13.70 \%$ \\
\hline $\begin{array}{l}\text { Mukherjee } \\
\text { et al }{ }^{17}\end{array}$ & 2013 & $P$ & 36 & CAP $830 \mathrm{mg} / \mathrm{m}^{2}$ & 63.1 & $50.4 \mathrm{~Gy} / \mathrm{I} .8 \mathrm{~Gy} / 28 \mathrm{Fx}$ & NR & 15.2 & 12 & $23 \%$ \\
\hline
\end{tabular}

Abbreviations: OS, overall survival; PFS, progression-free survival; ORR, objective response rate; GEM, gemcitabine; CAP, capecitabine; NR, not reported; P, prospective; $\mathrm{R}$, retrospective; 3D-CRT, three-dimensional conformal radiotherapy; Gy, gray; Fx, fraction.

Table 2 Baseline characteristics of concurrent radiotherapy with GEM versus oral FU

\begin{tabular}{llll}
\hline & $\begin{array}{l}\text { GEM } \\
\text { therapy }\end{array}$ & $\begin{array}{l}\text { Oral FU } \\
\text { therapy }\end{array}$ & P-value \\
\hline Cohorts, $\mathrm{n}$ & 14 & 9 & $\mathrm{~N} / \mathrm{A}$ \\
Patients, $\mathrm{n}$ & 497 & 346 & $\mathrm{~N} / \mathrm{A}$ \\
Median age, years & $64.7(59-68.5)$ & $63.1(58-67.5)$ & 0.69 \\
Median PFS & 6.4 & 8.7 & 0.22 \\
Median OS & $\mathrm{II} .2$ & 14.3 & 0.07 \\
Median radiation dose, Gy & 50.4 & 50.4 & 0.15 \\
\hline
\end{tabular}

Abbreviations: GEM, gemcitabine; FU, fluoropyrimidines; PFS, progression-free survival; OS, overall survival; $N / A$, not available. from the GITSG in $1981,{ }^{6}$ chemoradiotherapy for inoperable adenocarcinoma of the pancreas has been a standard treatment in the US. According to the National Comprehensive Cancer Network (NCCN) guidelines version 2, 2014, ${ }^{36}$ both 5-fluorouracil and GEM-based CRT are recommended for patients with non-metastatic LAPC, although several small RCTs ${ }^{9,10,37}$ and one meta-analysis ${ }^{11}$ suggested that GEM-based CRT seemed better than 5-fluorouracil-based CRT. Recently, two novel oral FU drugs, capecitabine and $\mathrm{S}-1$, have shown favorable antitumor activity when used in 


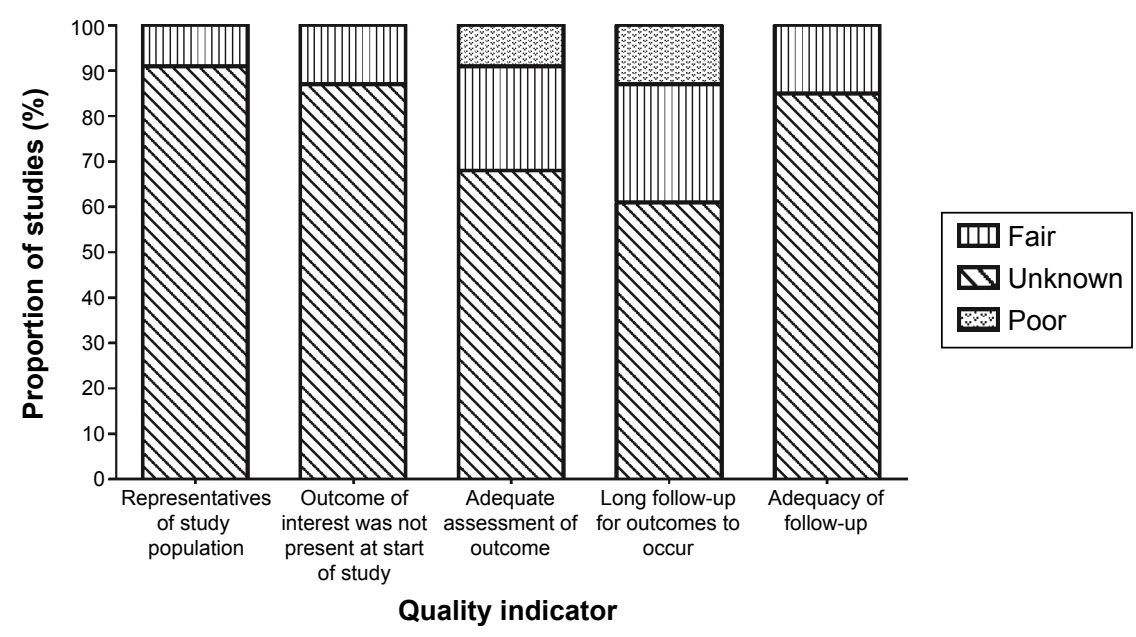

Figure 2 Selected methodological quality indicator.

combination with RT for treating LAPC in the concurrent setting; thus, both of these drugs are regarded as promising agents for the management of LAPC. However, to the best of our knowledge, there is lack of head-to-head comparison data available for oral FU versus GEM-based CRT in the treatment of LAPC, excepting one small RCT conducted by Mukherjee et al. ${ }^{17}$ In that trial, the authors concluded that capecitabine-based CRT might be preferable to GEM-based CRT for LAPC, but these findings should be interpreted with caution due to a non-significant difference between the two regimens and the relatively small sample size. ${ }^{17}$ As a result, we conducted the current systematic review and meta-analysis to evaluate the efficacy and toxicities of oral FU-based CRT compared with GEM-based CRT for the treatment of LAPC.
A total of 843 patients from 23 studies met the inclusion criteria and were used in the meta-analysis. Based on pooled results, we found that S-1-based CRT resulted in a statistically increased 1- and 2-year survival, but not for 1 -year PFS and ORR, while comparable efficacy was found to be comparable between capecitabine-based CRT and GEM-based CRT in terms of OS, PFS, and ORR. Additionally, our results indicated that oral FU-based CRT is also advantageous in reducing treatment toxicity in LAPC when compared to GEM-based CRT. However, more evidence is still required before oral FU-based CRT can become the standard treatment for LAPC patients. We could not pool the results about quality of life (QoL) due to only one trial ${ }^{17}$ reporting QoL results, and a detailed QoL analysis is planned by the authors of the current review.

Table 3 Comparison of primary outcomes for oral FU versus GEM-based chemoradiotherapy

\begin{tabular}{|c|c|c|c|c|c|c|}
\hline Groups & Cohorts, $n$ & Patients, $\mathbf{n}$ & Incidence, n (95\% CI) & $I^{2}$ & Relative risk (95\%) & $P$-value \\
\hline \multicolumn{7}{|l|}{ ORR } \\
\hline GEM & 12 & 399 & $23.4(\mid 4.5-25.6)$ & 80.2 & I & Ref \\
\hline Capecitabine & 5 & 177 & $22.7(14.0-34.7)$ & 60.9 & $0.97(0.57-1.66)$ & 0.45 \\
\hline S-I & 4 & 169 & $30.5(22.6-32.9)$ & 0 & $1.30(0.93-1.83)$ & 0.06 \\
\hline \multicolumn{7}{|l|}{ I-year OS } \\
\hline GEM & 12 & 431 & $49.6(40.8-58.5)$ & 67.6 & I & Ref \\
\hline Capecitabine & 5 & 177 & $57.1(4 I .9-7||)$. & 72.7 & $1.15(0.84-1.59)$ & 0.19 \\
\hline$S-1$ & 4 & 169 & $63.4(51.2-74.0)$ & 56.8 & $1.27(1.00-1.65)$ & 0.03 \\
\hline \multicolumn{7}{|l|}{ 2-year OS } \\
\hline GEM & 7 & 275 & I5.I (II.2-19.9) & 0 & I & Ref \\
\hline Capecitabine & 2 & 91 & II.0 (5.9-19.4) & 0 & $0.73(0.38-1.4 I)$ & 0.17 \\
\hline S-I & 3 & 144 & $26.5(20-34.3)$ & 0 & $1.75(1.18-2.60)$ & 0.002 \\
\hline \multicolumn{7}{|l|}{ I-year PFS } \\
\hline GEM & 5 & 206 & $27.5(\mid 1.7-52.1)$ & 87.3 & I & \\
\hline Capecitabine & 2 & 66 & $36.3(10.7-72.9)$ & 89.0 & $1.32(0.39-4.45)$ & 0.33 \\
\hline$S-1$ & 3 & 135 & $31.5(24.2-39.8)$ & 0 & I. $15(0.52-2.52)$ & 0.37 \\
\hline
\end{tabular}

Note: $l^{2} \geq 50 \%$ suggests high heterogeneity across studies.

Abbreviations: GEM, gemcitabine; FU, fluoropyrimidine; ORR, objective response rate; OS, overall survival; PFS, progression-free survival; Cl, confidence interval; Ref, reference group. 
Table 4 Comparison of $\geq$ grade 3 acute toxic effect event rates for oral FU versus GEM-based chemoradiotherapy

\begin{tabular}{|c|c|c|c|c|c|c|c|}
\hline & $\begin{array}{l}\text { Studies included } \\
\text { for analysis (n) }\end{array}$ & Events & Total & $\begin{array}{l}\text { Events rate, \% } \\
(95 \% \mathrm{Cl})\end{array}$ & $P^{2}$ & $\operatorname{RR}(95 \% \mathrm{Cl})$ & $P$-value \\
\hline \multicolumn{8}{|c|}{ Hematologic toxicity } \\
\hline \multicolumn{8}{|l|}{ Anemia } \\
\hline GEM & 12 & 23 & 407 & $8.5(5.8-12.3)$ & 36.3 & 1 & \\
\hline Oral FU & 9 & 4 & 346 & $2.3(1.1-4.7)$ & 0 & $0.27(0.12-0.61)$ & $<0.001$ \\
\hline \multicolumn{8}{|l|}{ Leukopenia } \\
\hline GEM & 12 & 83 & 407 & $19.7(\mid 2.8-29.1)$ & 72.3 & 1 & \\
\hline Oral FU & 9 & 12 & 346 & $6.0(3.6-9.7)$ & 5.1 & $0.30(0.16-0.58)$ & $<0.001$ \\
\hline \multicolumn{8}{|c|}{ Thrombocytopenia } \\
\hline GEM & 12 & 25 & 407 & $8.4(5.8-12.1)$ & 25.5 & 1 & \\
\hline Oral FU & 9 & 2 & 346 & $1.8(0.8-4.1)$ & 0 & $0.21(0.09-0.52)$ & $<0.001$ \\
\hline \multicolumn{8}{|c|}{ Non-hematologic toxicity } \\
\hline \multicolumn{8}{|l|}{ Nausea } \\
\hline GEM & 10 & 44 & 342 & | $3.8(8.6-2 \mid .5)$ & 58.3 & 1 & \\
\hline Oral FU & 8 & 7 & 286 & $4.8(2.5-9.0)$ & 12.3 & $0.35(0.18-0.66)$ & $<0.001$ \\
\hline \multicolumn{8}{|l|}{ Vomiting } \\
\hline GEM & 10 & 30 & 342 & I $2.2(8.7-\mid 7.0)$ & 47.9 & 1 & \\
\hline Oral FU & 8 & 2 & 286 & $2.1(0.9-4.9)$ & 0 & $0.17(0.69-0.43)$ & $<0.001$ \\
\hline \multicolumn{8}{|l|}{ Diarrhea } \\
\hline GEM & 8 & 15 & 296 & $6.1(3.8-9.7)$ & 0 & 1 & \\
\hline Oral FU & 8 & 3 & 286 & $3.1(1.4-6.5)$ & 0 & $0.5 \mathrm{I}(0.2 \mathrm{I}-1.25)$ & 0.07 \\
\hline \multicolumn{8}{|l|}{ Fatigue } \\
\hline GEM & 7 & 23 & 230 & $9.0(4.0-19.0)$ & 66.9 & 1 & \\
\hline Oral FU & 6 & 5 & 212 & $3.5(1.6-7.4)$ & 0 & $0.39(0.13-1.16)$ & 0.05 \\
\hline
\end{tabular}

Abbreviations: FU, fluoropyrimidine; GEM, gemcitabine; RR, relative risk; $\mathrm{Cl}$, confidence interval.

Several limitations exist in the present analysis. First and most importantly, the application of formal meta-analytic methods to observational studies has been controversial. ${ }^{38}$ One of the most important reasons for this is that the designs and populations of reviewed studies are often diverse, and these differences may influence the pooled estimates. However, when only one small RCT is available, a meta-analysis of observational studies is one of the few methods available for assessing efficacy and toxicities. ${ }^{39}$ Moreover, meta-analysis reduces the uncertainty surrounding the pooled estimates, and is a valuable method to inform the decision whether more evidence is needed, which is a timely discussion topic with regard to chemoradiotherapy in LAPC. However, potential bias may have occurred in the current review due to selection bias. Finally, the present meta-analysis only considers published literature, and lack of individual patient data prevented us from adjusting the treatment effect according to disease and patient variables.

\section{Conclusion}

Currently available clinical evidence for LAPC indicates that oral FU plus RT may be a safe and feasible regimen for patients with LAPC, with similar efficacy and low rate of toxicities compared with GEM plus RT. However, the overall quantity and quality of data regarding oral FU and GEM-based CRT are poor. The reported results do not allow for definite conclusions. As a result, prospective randomized studies, definitively comparing the survival and treatment toxicity between oral FU and GEM-based CRT, are strongly encouraged to clearly set the role of oral FU-based CRT in the treatment of LAPC.

\section{Acknowledgment}

We are indebted to the authors of the primary studies, for without their contributions, this work would have been impossible.

\section{Disclosure}

The authors report no conflicts of interest in this work.

\section{References}

1. Jemal A, Bray F, Center MM, Ferlay J, Ward E, Forman D. Global cancer statistics. CA Cancer J Clin. 2011;61(2):69-90.

2. Burris HA 3rd, Moore MJ, Andersen J, et al. Improvements in survival and clinical benefit with gemcitabine as first-line therapy for patients with advanced pancreas cancer: a randomized trial. J Clin Oncol. 1997; 15(6):2403-2413.

3. Gastrointestinal Tumor Study Group. Treatment of locally unresectable carcinoma of the pancreas: comparison of combined-modality therapy (chemotherapy plus radiotherapy) to chemotherapy alone. J Natl Cancer Inst. 1988;80(10):751-755.

4. Loehrer PJ Sr, Feng Y, Cardenes H, et al. Gemcitabine alone versus gemcitabine plus radiotherapy in patients with locally advanced pancreatic cancer: an Eastern Cooperative Oncology Group trial. J Clin Oncol. 2011;29(31): $4105-4112$. 
5. Chauffert B, Mornex F, Bonnetain F, et al. Phase III trial comparing intensive induction chemoradiotherapy (60 Gy, infusional 5-FU and intermittent cisplatin) followed by maintenance gemcitabine with gemcitabine alone for locally advanced unresectable pancreatic cancer. Definitive results of the 2000-01 FFCD/SFRO study. Ann Oncol. 2008; 19(9):1592-1599.

6. Moertel CG, Frytak S, Hahn RG, et al; the Gastrointestinal Tumor Study Group. Therapy of locally unresectable pancreatic carcinoma: a randomized comparison of high dose (6000 rads) radiation alone, moderate dose radiation (4000 rads +5 -fluorouracil), and high dose radiation + 5-fluorouracil. Cancer. 1981;48(8):1705-1710.

7. de Lange SM, van Groeningen CJ, Meijer OW, et al. Gemcitabineradiotherapy in patients with locally advanced pancreatic cancer. Eur J Cancer. 2002;38(9):1212-1217.

8. Varadhachary GR, Wolff RA, Crane $\mathrm{CH}$, et al. Preoperative gemcitabine and cisplatin followed by gemcitabine-based chemoradiation for resectable adenocarcinoma of the pancreatic head. J Clin Oncol. 2008; 26(21):3487-3495.

9. Li CP, Chao Y, Chi KH, et al. Concurrent chemoradiotherapy treatment of locally advanced pancreatic cancer: gemcitabine versus 5-fluorouracil, a randomized controlled study. Int J Radiat Oncol Biol Phys. 2003 57(1):98-104.

10. Park JK, Ryu JK, Lee JK, et al. Gemcitabine chemotherapy versus 5-fluorouracil-based concurrent chemoradiotherapy in locally advanced unresectable pancreatic cancer. Pancreas. 2006;33(4):397-402.

11. Zhu CP, Shi J, Chen YX, Xie WF, Lin Y. Gemcitabine in the chemoradiotherapy for locally advanced pancreatic cancer: a meta-analysis. Radiother Oncol. 2011;99(2):108-113.

12. Moher D, Liberati A, Tetzlaff J, Altman DG; PRISMA Group. Preferred reporting items for systematic reviews and meta-analyses: the PRISMA statement. Int J Surg. 2010;8(5):336-341.

13. Wells GA, Shea B, O'Connell D, et al. The Newcastle-Ottawa Scale (NOS) for assessing the quality of nonrandomised studies in metaanalyses. Ottawa, ON: Ottawa Hospital Research Institute; 2014. Available from: http://www.ohri.ca/programs/clinical_epidemiology/ oxford.asp. Accessed August 22, 2014.

14. Sterzing F, Brunner TB, Ernst I, et al. Stereotactic body radiotherapy for liver tumors: principles and practical guidelines of the DEGRO Working Group on Stereotactic Radiotherapy. Strahlenther Onkol. 2014; 190(10):872-881.

15. Altman DG, Bland JM. Interaction revisited: the difference between two estimates. BMJ. 2003;326(7382):219.

16. Duval S, Tweedie R. Trim and fill: a simple funnel-plot-based method of testing and adjusting for publication bias in meta-analysis. Biometrics. 2000;56(2):455-463.

17. Mukherjee S, Hurt CN, Bridgewater J, et al. Gemcitabine-based or capecitabine-based chemoradiotherapy for locally advanced pancreatic cancer (SCALOP): a multicentre, randomised, phase 2 trial. Lancet Oncol. 2013;14(4):317-326.

18. Kim YJ, Lee WJ, Woo SM, et al. Comparison of capecitabine and 5-fluorouracil in chemoradiotherapy for locally advanced pancreatic cancer. Radiat Oncol. 2013;8:160.

19. Ikeda M, Ioka T, Ito Y, et al. A multicenter phase II trial of S-1 with concurrent radiation therapy for locally advanced pancreatic cancer. Int J Radiat Oncol Biol Phys. 2013;85(1):163-169.

20. Wang BH, Cao WM, Yu J, Wang XL. Gemcitabine-based concurrent chemoradiotherapy versus chemotherapy alone in patients with locally advanced pancreatic cancer. Asian Pac J Cancer Prev. 2012;13(5):2129-2132.

21. Shinchi H, Maemura K, Mataki Y, et al. A phase II study of oral S-1 with concurrent radiotherapy followed by chemotherapy with S-1 alone for locally advanced pancreatic cancer. J Hepatobiliary Pancreat Sci. 2012;19(2):152-158.

22. Sudo K, Yamaguchi T, Ishihara T, et al. Phase II study of oral S-1 and concurrent radiotherapy in patients with unresectable locally advanced pancreatic cancer. Int J Radiat Oncol Biol Phys. 2011;80(1): $119-125$.
23. Huang J, Robertson JM, et al. Long-term results of full-dose gemcitabine with radiation therapy compared to 5-fluorouracil with radiation therapy for locally advanced pancreas cancer. Radiother Oncol. 2011;99(2): 114-119.

24. Cardenes HR, Moore AM, et al. A phase II study of gemcitabine in combination with radiation therapy in patients with localized, unresectable, pancreatic cancer: a Hoosier Oncology Group study. Am J Clin Oncol. 2011;34(5):460-465.

25. Kim HS, Yi SY, Jun HJ, et al. Definitive chemoradiation therapy with capecitabine in locally advanced pancreatic cancer. Anticancer Drugs. 2010;21(1):107-112.

26. Jackson AS, Jain P, Watkins GR, et al. Efficacy and tolerability of limited field radiotherapy with concurrent capecitabine in locally advanced pancreatic cancer. Clin Oncol (R Coll Radiol). 2010;22(7) 570-577.

27. Kim HM, Bang S, Park JY, et al. Phase II trial of S-1 and concurrent radiotherapy in patients with locally advanced pancreatic cancer. Cancer Chemother Pharmacol. 2009;63(3):535-541.

28. Small W Jr, Berlin J, Freedman GM, et al. Full-dose gemcitabine with concurrent radiation therapy in patients with nonmetastatic pancreatic cancer: a multicenter phase II trial. J Clin Oncol. 2008;26(6): 942-947.

29. Yamazaki H, Nishiyama K, Koizumi M, et al. Concurrent chemoradiotherapy for advanced pancreatic cancer: $1,000 \mathrm{mg} / \mathrm{m}^{2}$ gemcitabine can be administered using limited-field radiotherapy. Strahlenther Onkol. 2007;183(6):301-306.

30. Saif MW, Black G, Roy S, et al. Phase II study of capecitabine with concomitant radiotherapy for patients with locally advanced pancreatic cancer: up-regulation of thymidine phosphorylase. Cancer J. 2007; 13(4):247-256.

31. Murphy JD, Adusumilli S, Griffith KA, et al. Full-dose gemcitabine and concurrent radiotherapy for unresectable pancreatic cancer. Int J Radiat Oncol Biol Phys. 2007;68(3):801-808.

32. Magnino A, Gatti M, Massucco P, et al. Phase II trial of primary radiation therapy and concurrent chemotherapy for patients with locally advanced pancreatic cancer. Oncology. 2005;68(4-6):493-499.

33. Okusaka T, Ito $\mathrm{Y}$, Ueno $\mathrm{H}$, et al. Phase II study of radiotherapy combined with gemcitabine for locally advanced pancreatic cancer. Br J Cancer. 2004;91(4):673-677.

34. Blackstock AW, Tepper JE, Niedwiecki D, Hollis DR, Mayer RJ, Tempero MA. Cancer and leukemia group B (CALGB) 89805: phase II chemoradiation trial using gemcitabine in patients with locoregional adenocarcinoma of the pancreas. Int $J$ Gastrointest Cancer. 2003; 34(2-3):107-116.

35. Epelbaum R, Rosenblatt E, Nasrallah S, et al. Phase II study of gemcitabine combined with radiation therapy in patients with localized, unresectable pancreatic cancer. J Surg Oncol. 2002;81(3): $138-143$.

36. National Comprehensive Cancer Network [webpage on the Internet]. Clinical practice guidelines in oncology (NCCN guidelines) pancreatic adenocarcinoma, version 2. Fort Washington, PA: National Comprehensive Cancer Network; 2014. Available from: http://www.nccn.org/ professionals/physician_gls/f_guidelines.asp\#pancreatic. Accessed October 10, 2014.

37. Tada M, Arizumi T, Nakai Y, et al. Efficacy of gemcitabine for locally advanced pancreatic cancer: comparison with 5-fluorouracil-based chemoradiotherapy. Chemotherapy. 2008;54(4):302-308.

38. Blettner M, Sauerbrei W, Schlehofer B, Scheuchenpflug T, Friedenreich C. Traditional reviews, meta-analyses and pooled analyses in epidemiology. Int J Epidemiol. 1999;28(1):1-9.

39. Stroup DF, Berlin JA, Morton SC, et al. Meta-analysis of observational studies in epidemiology: a proposal for reporting. Meta-analysis Of Observational Studies in Epidemiology (MOOSE) group. JAMA. 2000; 283(15):2008-2012 


\section{Supplementary material}

Table SI Newcastle-Ottawa quality assessment scale

\section{Selection}

I. Representativeness of the exposed cohort

a) Truly representative of the average CRC pancreatic cancer patients in the community ( $\star$ )

b) Somewhat representative of the average CRC pancreatic cancer patients in the community ( $\star$ )

c) Selected group of users (eg, nurses, volunteers)

d) No description of the derivation of the cohort

2. Selection of the non-exposed cohort

a) Drawn from the same community as the exposed cohort $(\star)$

b) Drawn from a different source

c) No description of the derivation of the non-exposed cohort

3. Ascertainment of exposure
a) Secure record (eg, surgical records) $(\star)$
b) Structured interview $(\star)$
c) Written self-report
d) No description

4. Demonstration that outcome of interest was not present at start of study
a) Yes $(\star)$
b) No

Comparability

I. Comparability of cohorts on the basis of the design or analysis

a) Study controls for metastasis or micro-metastasis $(\star)$

b) Study controls for any additional factor $(\star)$

\section{Outcome}

I. Assessment of outcome

a) Independent blind assessment $(\star)$

b) Record linkage $(\star)$

c) Self-report

d) No description

2. Was follow-up long enough for outcomes to occur?

a) Yes ( 2 years) $(\star)$

b) No

3. Adequacy of follow-up of cohorts

a) Complete follow-up - all subjects accounted for $(\star)$

b) Subjects lost to follow-up unlikely to introduce bias - small number lost $25 \%$ follow-up, or description of those lost ( $\star$ )

c) Follow-up rate $<75 \%$ and no description of those lost

d) No statement

Notes: The star symbol signifies that study quality score; more stars means the study has higher quality.

\section{Dovepress}

\section{Publish your work in this journal}

OncoTargets and Therapy is an international, peer-reviewed, open access journal focusing on the pathological basis of all cancers, potential targets for therapy and treatment protocols employed to improve the management of cancer patients. The journal also focuses on the impact of management programs and new therapeutic agents and protocols on

patient perspectives such as quality of life, adherence and satisfaction. The manuscript management system is completely online and includes a very quick and fair peer-review system, which is all easy to use. Visit http://www.dovepress.com/testimonials.php to read real quotes from published authors. 